\title{
DESIGNING HR ORGANIZATIONAL STRUCTURES IN TERMS OF THE HR BUSINESS PARTNER MODEL PRINCIPLES FROM THE PERSPECTIVE OF CZECH ORGANIZATIONS
}

\author{
Stř́íteský, M., Quigley, M. J. D.
}

This paper describes new trends related to the concepts contained in HR organizational structures within Czech organizations. In addition, it describes the specifics of the roles played by HR in those organizations which have transformed their HR departments in terms of the principles of the HR Business Partner Model, both in theory based on available resources, and at the practical level based on the results of primary examination. The goal of this paper is to present the key perceptions of the changes made in the HR structure within the organizations, as well as the impact of these changes on the effectiveness of the HR departments concerned. Another goal of the paper is to summarize the responsibilities of the newly created position known as the HR Business Partner in these organizations as well as the demands placed upon the personnel employed in the HR Business Partner role. The paper offers conclusions based on the results of both quantitative and qualitative surveys. It also contains a case study of one organization which has one of the best transformed HR departments, and whose services are classified, by internal clients, as being of high quality.

JEL classification: L22, M12, J21

Keywords: HR Organizational Structure; HR Transformation; HR Roles; HR Business Partner; Human Resource Management.

\section{Introduction}

The status and role of Human Resource managers in the field of strategic management are closely related to the importance attached to Human Resources in terms of the success and competitiveness of the given company. The impact of Human Resource Management is directly related to the increasing value and importance of the intangible assets for the organization (Dvořáková, 2012; Šikýř, 2013). This factor determines the significance of the role of HR Management within the company. This, in turn, reflects the Human Capital theory, according to which, the costs associated with the procedures and processes in Human Resources should be viewed as an investment that will generate income in the future (Becker, Huselid and Ulrich, 2001).

Developments and changes in the importance of Human Resources for companies have an impact on the dynamics and functioning of Human Resource departments themselves. The different expectations engendered by these changes are related primarily to the HR departments' strategic role; namely the important support which they provide to line managers in the latter's implementation of the companies' business strategy (Svoboda and Schroder, 2001). From this perspective, the frequently cited HR Business Partner Model distinguishes between four fundamental roles of HR in organization (Ulrich, 1997). The HR Business Partner Model is shown in Figure 1 (Ulrich, 1997).

\section{Figure 1 HR Business Partner Model}

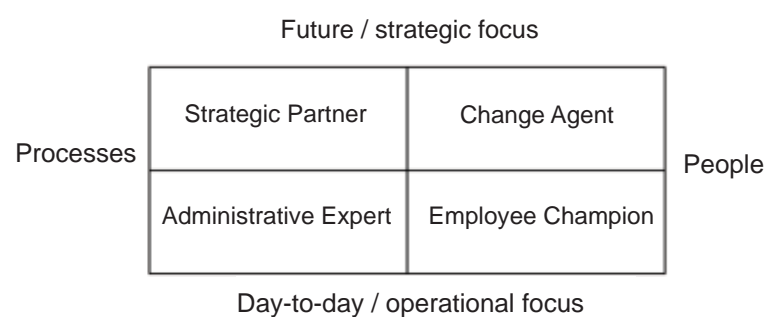

Source: Ulrich, D. (1997). Human Resource Champions: The next agenda for adding value and delivering results. (1st ed.). Harvard Business School Press. p. 34. 
These roles reflect the specific focus of the HR department in four dimensions, which consist of two axes; they serve to define the aspects of the business and people perspective on the one hand, and the strategic and operational point of view on the other (see Figure 1). In connection with this new concept of the HR role, many companies operating in the Czech Republic have transformed the structures of their Human Resources departments. This should enable the provision of better HR services to internal clients (top management, line managers, employees), as well as emphasizing the strategic function of HR departments (Labedz and Lee, 2011; Ulrich, 1997).

This paper deals with the issue of HR organizational structure transformation from the perspective of Ulrich's HR Business Partner Model in organizations operating in the Czech Republic. The goal of this paper is to present the key perceptions of the HR structure changes within the companies, as well as the impact of these changes on the effectiveness of HR departments. Another goal is to summarize responsibilities of the newly created position known as the HR Business Partner in these organizations, as well as the demands placed upon the personnel employed in the HR Business Partner role. All goals are achieved by means of primary data analyses. This data was received from a quantitative and qualitative survey, or from comparisons based on secondary resources.

The paper's contribution consists of the practical view it takes of the theoretical concepts contained in the HR Business Partner Model by Dave Ulrich, as well as the specific applications determined by the transformation of Human Resources departments in selected Czech companies, which reflect these concepts in different ways.

\section{Methods}

This paper achieves its goals through the analysis of the internal reports of the organizations, as well as the responses of those managers who were involved in the qualitative and quantitative research. The paper also compares the data obtained from HR practices, as well as the principles contained in the applied theory model. The sample analyzed in the quantitative research is made up of 97 Czech companies, each with more than 150 employees - regardless of the industry, or sector of the economy. Questionnaires were distributed to 294 organizations. In the end, 97 organizations returned completed questionnaires (this means: $61 \%$ were organizations with less than 500 employees and $39 \%$ were organizations with more than 500 employees; $14 \%$ of the organizations were from the primary sector, $54 \%$ of the organizations were from the secondary sector and $32 \%$ of the organizations were from the tertiary sector). The first part of the quantitative research was based on the answers given on the researchers' questionnaires by the managers of firms. The second part of the quantitative research was carried out with the cooperation of HR managers or other persons responsible for Human Resource Management in the organization. This research was focused on the perception of the role of Human Resources in the organization, as well as on the various aspects of Human Resources in the firm. The researchers concentrated especially on the structure of the HR department, and how the quality of the HR services inside the company is perceived. To achieve the goals related to organizations with an effective HR delivery model, the qualitative research was aimed at firms which have transformed their HR organizational structures, and whose managers have classed the HR delivery models as being effective in providing HR services of a higher quality (scoring at least 4 points on a 5 point scale). The qualitative research was based on interviews with company managers, as well as with HR managers of those companies which have transformed their HR departments' structures. In the qualitative research nine organizations were included (six organizations from the secondary sector and three organizations from the tertiary sector). In addition, the managers' perceptions of the high quality of the HR services were analyzed, as were such internal documents like job descriptions, organizational rules and regulations, organograms, and the like. Afterwards, a short case study was carried out on the successful solution (it can be regarded as an example of the best practice in this area). This dealt with the successful concept of the HR organizational structure after the implementation of the transformations reflecting the HR Business Partner Model. These represent the successful application of the important principles of the chosen theoretical model, as well as its impact on HR Management in the organization. The data collection part of the quantitative research was conducted from February 2012 to November 2012. The qualitative phase of the research was carried out from January 2013 to June 2013.

Secondary data are also used in this paper, mainly for comparison purposes. These data were obtained from the international survey carried out by Chartered Institute of Personnel Development (CIPD, 2012). Furthermore, the paper uses the research report issued by PricewaterhouseCoopers CR (PwC, 2013). This report was based on quantitative data from $153 \mathrm{Czech}$ organizations. The secondary data from the first survey consists of those facts which are related to the shifts in the perception of the HR role - both currently and in the 
future - within the international context. The secondary quantitative data from the second survey are used as a measure of the standard values of the key HR performance indicators which were analyzed, and which are used in Czech companies.

\section{HR Delivery Models Reflecting HR Business Partner Roles}

The traditional model can be represented as shown in Figure 2. Its disadvantages include the limited involvement of the Human Resources department in the management processes of other departments which are supported by the provision of HR services. There are only limited possibilities for the standardization and centralization of the administrative processes (aimed at cost savings and improved services) which would generate the resources necessary for Human Capital investment, as well as for other strategic activities (Dvořáková, 2012). Opportunities for the more effective sharing of HR knowledge and best practices are reduced within structures of this type. This is due to the fact that such knowledge is generated during interaction with the assigned business units. The transfer of this knowledge to other areas of the organization, in order to be used there, is not usually possible.
The organizational structure of the Human Resources department based on a Human Resource Business Partner Model might look like the one shown in Figure 3. Such a HR organizational structure enables the HR departments to implement its corporate strategy more effectively, as well as the management of its realization from the perspective of Human Resource Management.

A HR structure must match the business structure of the given company. For instance, a holding company business structure would lead to a decentralized and dispersed HR organization, while a single-business activity company would have a different type of HR department (Ulrich, 2007). This new type of HR department organizational structure allows HR departments to reflect the company's business structure in more effective and logical ways. HR Business Partners are directly assigned to the heads of the different departments of the given organization. This allows the organization to ensure a closer relationship between its Human Resources department and the rest of its business activities.

On the other hand, it is useful to split the many activities of the HR departments into their transactional and transformational activities. Transactional duties are routine and of an administrative nature; therefore they can and should be standardized. It is desirable to handle them

Figure 2 Traditional HR Department structure

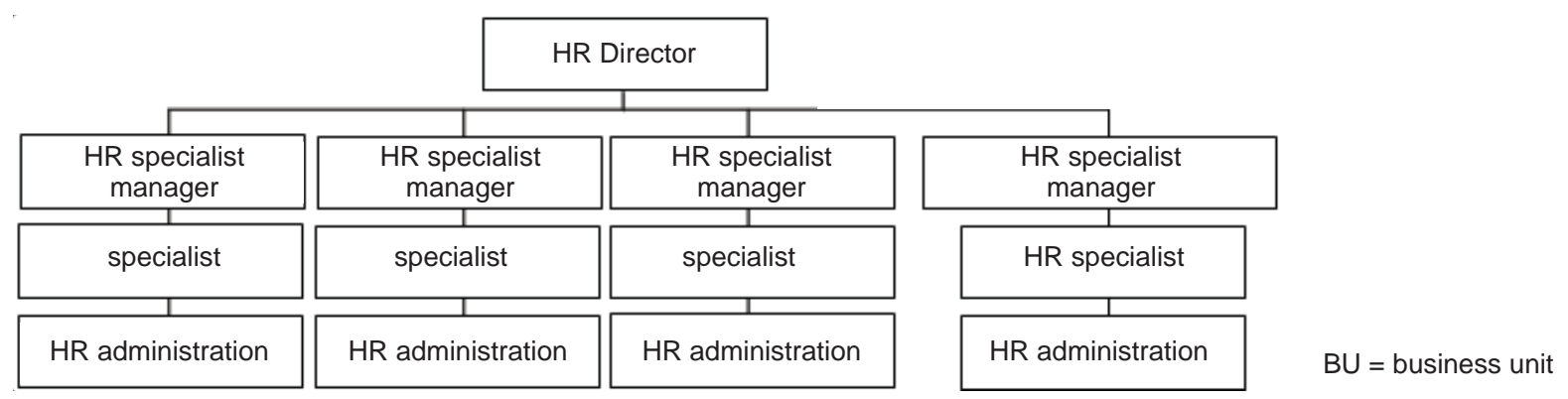

Source: Hunter, I. Saunders and J. Boroughs, A. (2006). HR Business Partners: Emerging Service Delivery for the HR. (1st ed.). Gower Publishing. (Adapted by the authors)

Figure 3 HR department structure based on HR Business Partner Model

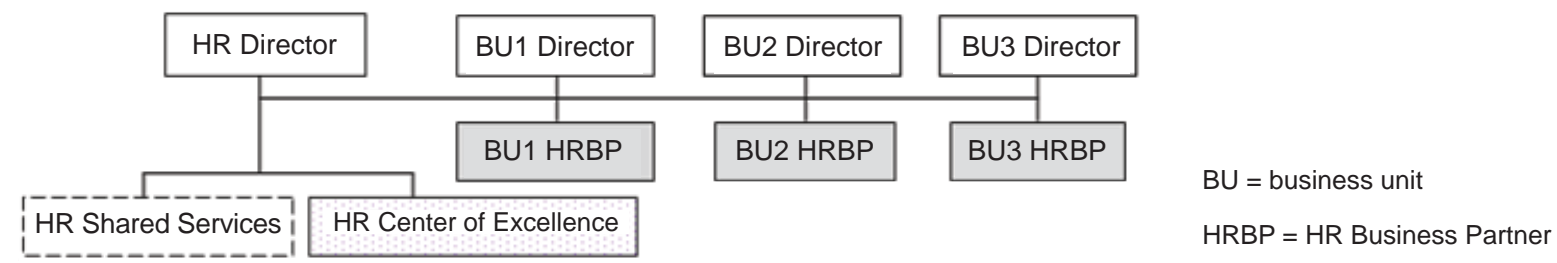

Source: Hunter, I. Saunders, J. Boroughs, A. (2006). HR Business Partners: Emerging Service Delivery for the HR. (1st ed.). Gower Publishing. (Adapted by the authors) 
Figure 4

Perception

of the HR Function

in Organizations

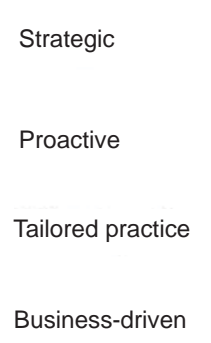

Specialist

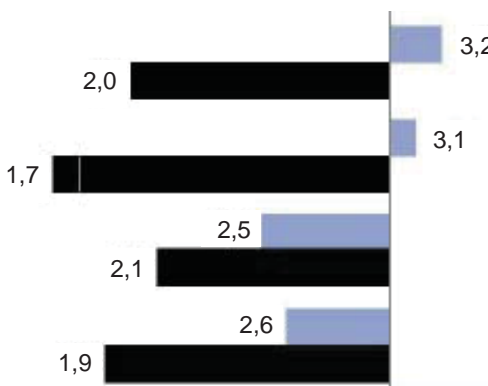

3,2

eactive

Off-the-shelf

Employee-driven

3,4

Generalist
2,7
Institute of Personnel

and Development, 2012.
Future

$\begin{array}{llcc}2 & 3 & 4 & 5 \\ & & \text { Now (2012) } & \text { Future }\end{array}$

through service centers, or outsourcing (Cascio, 2005). Transformational duties, which are differentiated and strategic, are concentrated in HR centers of expertise, as well as in groups of business partners. Transformational duties are also allocated to HR generalists, who mostly fulfil the strategic partner and change agent roles in the HR Business Partner Model (shown in Figure 1).

HR administrative processes are therefore a matter of shared service centers. These enable standardized access to the administrative processes, as well as facilitating fast and efficient implementation of personnel policy. Specialists and experts in Human Resources, working together in the center of expertise, are thus able to create a network of specialized knowledge which can be shared within the organization, and which the company can more fully utilize.

The transformation of HR structures is currently under consideration because companies are under increased pressure to perform Human Resources tasks more quickly and effectively. These activities are currently planned in organizations, and this trend has been confirmed by several surveys based on interviews with managers (McGrory, 2012). It is necessary to view this HR transformation as two journeys. There is an „efficiency“ journey, which rationalizes and modernizes HR processes, using shared service centers and business partners. Many organizations have already taken this journey and have realized impressive improvements in HR costs and transactional services. The second journey, which is regarded as the „next generation“ journey, is different and more ambitious. It enables HR to deliver strategic interventions and commercial results. This is a crucial journey, and one that few HR teams have made any progress on (Goodge, 2011). However, both of them include HR structure transformation, because structure is the key element of any organization and must be aligned with its strategy.

The position of the HR Business Partner has a number of features in common with the role of the Human Resources consultant, but they are not identical. The consultant is a role in which a person has a certain effect on the individual, group or organization, but does not have any direct power to make changes, or to implement any of the programs. We can distinguish between external and internal consultants. The know-how of the internal consultant is limited by the specifics of the particular organization. An external consultant has limited specific knowledge of the organization. In contrast, the internal consultant has greater knowledge related to the particular firm's culture and its employees. Thus, the HR Business Partner should be an internal consultant, but every internal consultant may does not necessarily have to be a HR Business Partner (Kenton and Yarnall, 2005).

The person in the function of the HR Business Partner must satisfy relatively high standards. In order to work well in this role, it is necessary to have both a detailed understanding of the business, from the operational and financial perspectives, as well as an understanding of the strategic aspects of the firm, in addition to having a knowledge of the ways of realizing the strategy within the organization, this mainly from the perspective of Human Resources (Lawler, 2005). As mentioned above, the HR Business Partner should have input into the decisions concerning Human Resources. This person should also be able to suggest a suitable HR strategy, based on an accurate estimation of the future development of the organization, and its implications for Human Resources (Armstrong, 2005). To aid in decision making, he needs access to a lot of information. Therefore, it is crucial for him to be accepted by others in the management team. 
For this reason, the HR Business Partner should be able to correctly initiate the process of defining, monitoring, clearly reporting and evaluating the impact of Human Resources on the business activities of the organization in order for him to be able to convince the managers of the utility of his role (Svoboda and Schroder, 2001).

Research has shown that the perceived role of Human Resources in business organizations is changing rapidly nowadays. This trend is documented in Figure 4. The Human Resources function has shifted from the purely administrative to the strategic level. This trend must be reflected in the HR structural transformation in order to support these changes, as well as fulfilling managers' expectations related to future HR roles in business organizations.

\section{Impact of HR Department Transformation on the Perception of the Role of HR Management as well as the Effectiveness of HR Departments}

The perception of the HR role and HR function in organizations after HR department transformation was analyzed through questioning managers in these organizations. The managers assessed the perception of the role and function of the HR departments in their organizations. They used a five point scale to do this. Figure 5 compares the perceptions of standard and transformed HR departments in Czech firms (these comparisons were based on primary data obtained from surveys carried out in Czech companies; 192 managers participated in the surveys).
The results show that the transformation of the HR organizational structure also means that a change has taken place in the perception of the role of HR in the organization. The role of the HR department is perceived more positively from the managerial point of view than it is in organizations whose HR departments still have the 'old' standard organizational structure. The HR department is more focused on the realization of the organizational strategy, as well as with supporting the company's business activities. In those organizations which still have the standard HR organizational structures in place, the HR department's role is perceived to be operational and administrative. This change in the perception of the strategic role of the HR departments is significant, and it can be influenced by the effects of the aforementioned changes in the HR departments in some of the firms which were examined in recent years. But only the existence of the position of the HR Business Partner, or that of the HR consultant in the HR department, has also, probably, contributed to this change in the perception of the role of HR in companies. These aspects of HR departments' activities have been acknowledged by some line managers as being helpful in the solution of problems specific to their departments. Thus, the HR departments can be seen as more strategically oriented, while supporting the business activities of the organization. On the other hand, it must not be forgotten that some line managers perceive the services provided by the HR department as being of relatively low quality.

Figure 5 Comparison of the perceptions of the role of HR departments (i.e., their functionality) in organizations with the standard HR organizational structure, with those of firms which have transformed HR organizational structures $(n=192)$

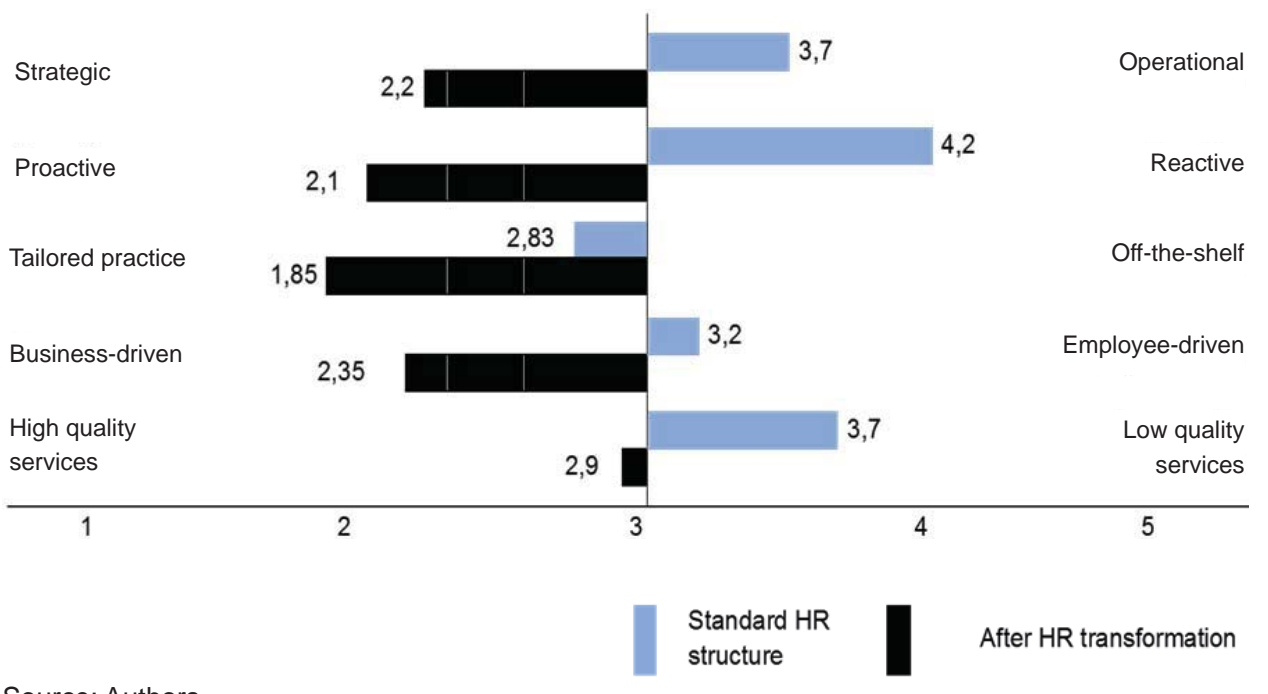

Source: Authors. 
Figure 6 Costs of HR per FTE comparison in Czech organizations with standard HR organizational structure $(n=48)$, Czech organizations with transformed HR organizational structure ( $n=34)$, Czech organizations included in the PwC survey $(n=153)$ in 2012
Source: Authors.

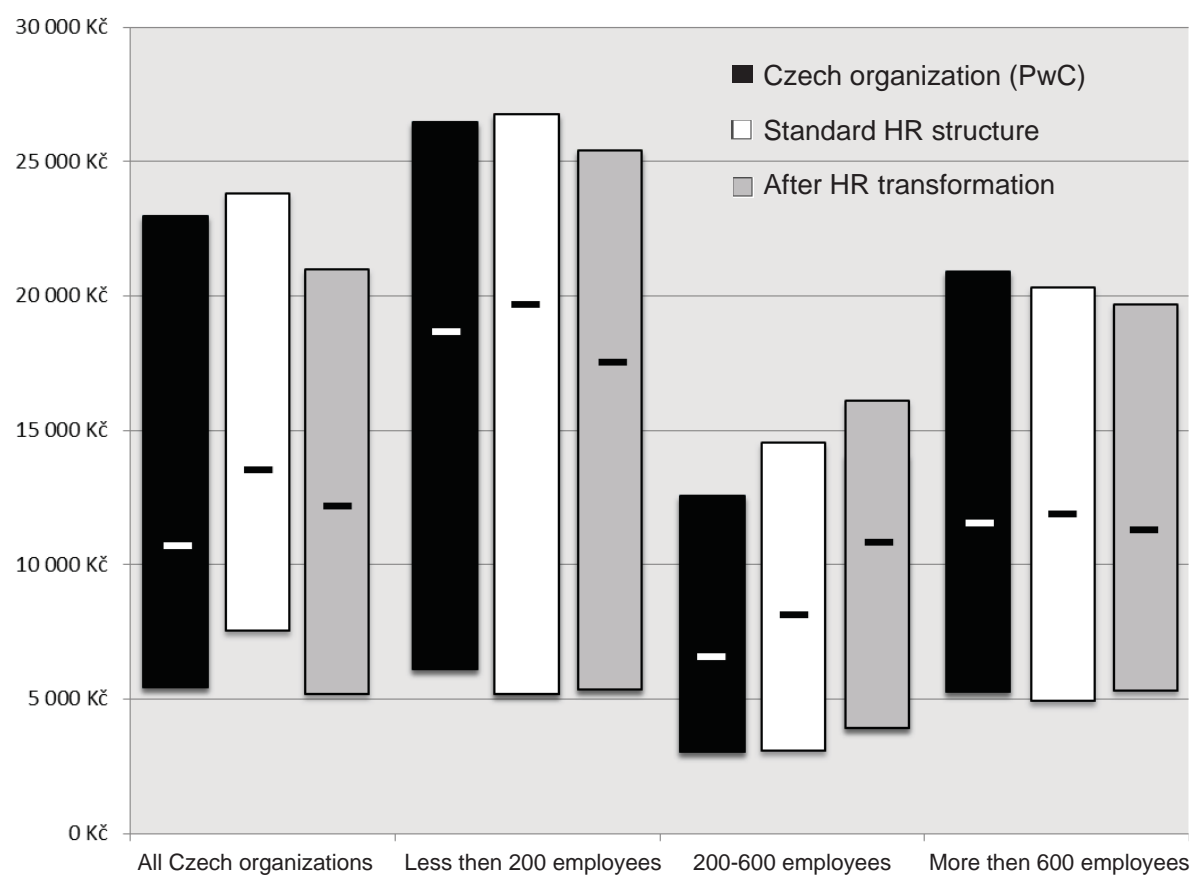

The quality of the transformed HR services is better than the quality of those offered by standard HR departments, but the evaluation of the level of HR services' quality (i.e. in trans-formed HR structures) is relatively low. Bad communications between line managers, HR Business Partners and HR specialists was cited as the main reason for the low quality of HR services. Other prime reasons for HR service insufficiencies were the inability to link HR and business strategies, as well the inability to incorporate HR policies into the practical life of the various line departments in the firm.

In addition to the changes in the perceptions of the HR role and function in the organizations, it is also necessary to examine the effect(s) which the transformation of the HR organizational structure has on the cost-effectiveness of HR departments. There are several ways to measure the cost effectiveness of the HR department. One of the simplest and most convenient indicators used for this purpose is the cost analysis of the particular HR department related to the FTEs (Full Time Equivalents - this expresses the number of employees of the organization). The comparison of HR department costs in organizations with transformed and standard HR department structures can be seen in Figure 6 (based on primary data analysis, as well comparison with secondary data from Czech organizations). This figure contains data for Czech organizations, and costs are measured in CZK. The data from a survey which was carried out by PriceWaterhouseCoopers CR were used as an example of the standard values for the indicator costs of HR departments related to the FTEs in the Czech Republic. These data were comprised of samples taken from 153 Czech organizations (PwC, 2013). The graph in Figure 6 shows the values ranked according to the size of the organization. This was measured by the number of employees. The values shown range from 25 to 75 percentage points. In particular, there is a middle value marked for each category of sample that was surveyed.

The impact of the transformation of the HR organizational structure on the HR department's effectiveness is not clear. In most of the groups of organizations which were examined, it is possible to discern positive differences between those departments which have modern structures of employees, and those with the standard structure. However, these differences cannot be considered significant. Furthermore, in the category of organizations which have 200 to 600 employees, the difference is negative. In addition, the comparisons made with the data which express the standard values for Czech organizations (i.e., the PwC survey) lead to unclear, or negative, conclusions.

The unclear impact which transformation has on the HR organizational structure applies to the main reasons for that transformation. The main purpose of this transformation is not cost reduction in HR departments. Cost aspects are considered only in the case of those administrative processes which are characterized by low added value. The basic principles of HR transformation 
projects in organizations are such aspects as the strengthening of the strategic focus of HR; its focus on the internal and external clients, as well as a better alignment of HR and the business itself. The reduction of the costs of the administrative processes is realized through their rationalization, centralization or outsourcing. This should mobilize the resources for client-oriented HR departments.

\section{Transformation of the HR Organizational Structure as an example of Best Practice (case study)}

The organization reflects the HR Business Partner Model and presents the question of HR transformation, as well as the way the HR organizational structure is dealt with in a company from the Chemical Industry. This can be used as an example of best practices in the HR area because of the positive evaluation received by the quality of HR services from the managers in this organization. When the managers evaluated the quality of the HR services, they gave at least 4 points on a 5 point scale in this survey. The case study focuses on the following aspects: transformation issues, the new HR department structure, specific issues in the role of the HR Business Partner (or an equivalent role in the HR department). This part of the paper presents some of the results of the qualitative survey which was realized in nine organizations in the Czech Republic in 2012.

Values in the Human Resources section of the company are: strategic partnerships, added value, reliable service, international orientation as well as the promotion of change. It was decided to transform the structure of the Human Resources department on the basis of these values. The main objective of this transformation of the HR department was to provide internal clients with services of a higher quality, as well as becoming a respected partner for the other departments within the company. These objectives are connected with many aspects; from the new goals of the HR department and $\mathrm{HR}$ processes transformation to the modern HR Management approaches, including the more developed HR quality control system. It also includes changes in HR roles, as well as changes in the HR department's organizational structure.

The entire transformation process has been working towards the design of a system for a professional HR service center. This system is meant to standardize the key HR processes, and the internal client approach, including their measurability. The system should also lead to the streamlining of the administrative processes in Human Resources, the implementation of a consistent reward system throughout the organization, as well as improving Human Resources supervision and reporting. Previously, the HR department was divided into the front office and back office. During the course of the transformation, the new position of the HR Business Partner was created. This role had been assigned, initially, to internal HR consultants. The activities of the HR Business Partner in the organization include the provision of broader support for the internal clients. In addition, it carries more responsibility than does the role of HR consultant. Some examples of this responsibility are: responsibility for the execution of the HR processes, the implementation of HR standards, participation in business projects, cooperation with internal and external service providers, overseeing the adaptation of new employees to the corporate culture as well as dealing with operational issues. All this is in addition to the daily HR agenda. The back office consists of four expert teams which focus on training and development, compensation and benefits, HR supervision, as well as HR projects. The HR administration department deals with the run of the mill HR activities.

The diagram in Figure 7 (based on the results of the qualitative research, which consisted of interviews with managers, and analyses of the internal documents of the

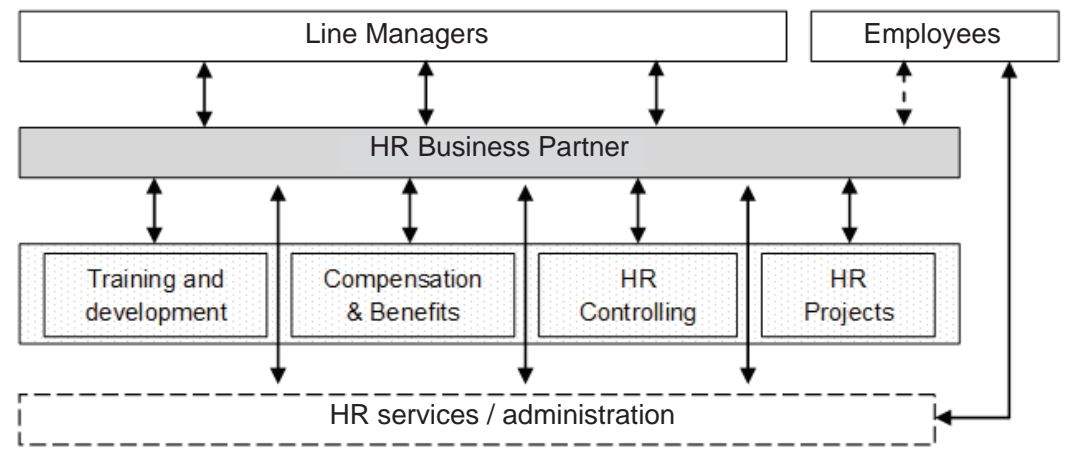

Figure 7 Structure of HR department after the transformation 
organization) illustrates the link between the HR Business Partner and the line manager. The HR Business Partner deals with requests from the assigned line departments, either alone or he passes them to the back office. Within this scheme, it is possible to define the main responsibilities within the HR department. Back office departments (e.g., the Training and Development department, Compensation \& Benefits department, HR Supervisory department, HR Projects department) are responsible for creating the HR tools and systems (e.g. the performance management system, employee appraisal tools, the system of employee training and development, the system of talent management, etc.). The HR Business Partner is responsible for their implementation in cooperation with the assigned line managers.

\section{Conclusion}

From the data and case study presented above, it is possible to arrive at some conclusions which also have implications for the management of the organization as a whole. Among the most important of these are the goals of the HR transformation projects in Czech companies, as well as their impact on the effectiveness of HR departments. Other important factors, too, are the demands placed upon HR managers, which arise from their newly allocated areas of competence, as well as the benefits arising from these transformation projects as perceived by the managers of these organizations.

The companies which have successfully transformed their HR departments, and were included in the qualitative survey, are very dynamic organizations occupying leading positions in their business spheres. Transformation of the Human Resources departments was mostly linked to changes throughout the organization as a reaction to market trends, as well as to those in the competitive environment. It could be said that the main reason for the transformation which was carried out in Human Resources departments in those Czech organizations which were surveyed, was the need to make an effort to change the role and importance of those Human Resources departments from being mainly administrative and operational. Instead, the aim was to increase the HR departments' involvement in the strategic aspects of managerial decisions, thus adding higher value to most of these departments' activities. This development, it is hoped, will lead to the transformed HR departments becoming respected and equal partners to senior management, by virtue of their valuable contributions to the strategic decision making processes. Another goal was to strengthen client focus, and improve the quality of HR services to internal clients. Among the other reasons for the transformation is the improved measurability of Human Resources processes. This includes their simplification, standardization and economization. Last, but not least, are the costs optimization, and improvements in the methods of controlling and reporting.

The new, post-transformation structure divides the HR departments in these organizations into front office and back office. The back office is made up of expert teams and/or administrative departments. Expert teams are mostly focused on development, knowledge management and training, compensation and benefits and/or recruitment. Furthermore, there are departments dealing with HR Supervision, HR projects and information management.

The front office is represented by a newly created function, that of the HR Business Partner. His daily workload is characterized by the minor differences existing within each organization. In some organizations it is closer to the role of the Strategic Partner; sometimes he performs the role of the internal HR consultant. Regarding the competence profile of the HR Business Partners, the following skills are required of the ideal person for the position: a good grasp of the business; analytical skills; a constructive approach to problem solving; the ability to perceive needs in advance, as well as the ability to act proactively. He must also be communicative and have organizational skills, as well as having a natural authority.

Regarding the benefits arising from this transformation in the Czech companies, we can cite: improved quality of HR services, higher efficiency and standardization of HR processes, as well as the channeling of efforts into strategic HR activities, and better support from line managers. However, what remains unclear is the impact of the HR organizational structure transformation in Czech organizations on cost reduction in HR departments. Some positive relations are not significant. The purpose of this transformation is not to reduce total costs of HR departments; rather, it is to mobilize resources in order to strengthen the strategic impact of HR on the organization, as well as supporting the client-oriented approach and to focus HR departments on activities with higher added value.

\section{References}

Armstrong, G. (2005). Differentiation through people: How can HR move beyond business partner? Human Resource Management, 44(2): 195-199.

Block, P. (2001). The flawless consulting field book \& companion: A guide to understanding your expertise. San Francisco: Jossey-Bass/Pfeiffer. 
Cascio, W. F. (2005). From business partner to driving business success: The next step in the evolution of HR management. Human Resource Management, 44(2): $159-163$.

CIPD. (2012). The changing hr function, [available at: http:// www.cipd.co.uk/NR/rdonlyres/9FC78BA5-B992-40B885ED-8FA5C3F9FACC/0/chnghrfunc.pdf].

Dvořáková, Z. (2012). Řízení lidských zdrojů. Prague: C.H. Beck.

Goodge, P. (2011). Transform HR. Strategic HR Review, 10(2): 40-41.

Hunter, I., Boroughs, A., Saunders, J., Constance, S. (2006). HR Business Partners: Emerging Service Delivery for the HR. Aldershot: Gower Publishing, Ltd.

McGrory, A. (2012). More employers expect to modify HR structure. Benefits Selling. Breaking News.

Kenton, B., Yarnall, J. (2005). HR - The Business Partner: Shaping a New Direction. Oxford: Butterworth-Heinemann.

Labedz, C. S., Lee, J. (2011). The mental models of HR professionals as strategic partners. Journal of Management and Organization, 17(1): 56-76.

Lawler, Edward E. (2005). From human resource management to organizational effectiveness. Human Resource Management, 44(2): 165-169.

PwC. (2013). HR Controlling 2013, [available at: http://www. pwc.com/cz/cs/poradenstvi-pro-lidske-zdroje/paywelland-hr.jhtml].
Svoboda, M., Schroder, S. (2001). Transforming human resources in the new economy: Developing the next generation of global HR managers at deutsche bank AG. Human Resource Management, 40(3): 261-273.

Šikýř, M. (2013). Best Practices in Human Resource Management: The Source of Excellent Performance and Sustained Competitiveness. Central European Business Review, 2(1): 43-48.

Ulrich, D. (1997). Human resource champions: The next agenda for adding value and delivering results. Harvard: Harvard Business School Press.

Ulrich, D. (2007). The new HR organization. Workforce Management, 86(21): 40-42.

Authors

Ing. Marek Stříteský, Ph.D. Assistant Professor

Department of Human Resource Management Faculty of Business Administration University of Economics, Prague stritesm@vse.cz

Martin John David Quigley, BA, LL.B., LL.M. Research Assistant Department of Human Resource Management Faculty of Business Administration University of Economics, Prague martin.quigley@vse.cz 